\title{
Assessment of Water Quality of Himayathsagar Lake in Hyderabad - A Case study.
}

\author{
K.Padmaja ${ }^{1}$, Jyotsna Cherukuri ${ }^{2 *}$, M.Anji Reddy ${ }^{3}$ \\ ${ }^{I}$ (Assistant Professor, Department of Humanities and Sciences, VNR Vignana Jyothi Institute of Engineering and \\ Technology, Hyderabad, Telangana, India.) \\ ${ }^{2 *}$ (Associate Professor, Department of Humanities and Sciences, VNR Vignana Jyothi Institute of Engineering and \\ Technology, Hyderabad, Telangana,India) \\ 3(Director R \& D, Professor, Centre for Environment, Jawaharlal Nehru Technological University, Hyderabad,
} Telangana, India)

Abstract: Hyderabad is called 'Limnological capital of India, owing to greater number of major and minor water bodies in its metropolitan limits. Most of these water bodies are used as drinking water sources in the city. The study of water quality of Himayathsagar is taken up as this drinking water source is more susceptible to the growing urbanization and industrialization due to its close vicinity to Hyderabad city. The water quality index of the Lake using the physicochemical and biological parameters is calculated. The results showed slightly poor water quality of the lake. If all the activities leading to the deterioration of water quality are controlled in the catchment areas this precious resource can be saved for future use.

Keywords: Industrialization, Limnological, physicochemical parameters, urbanization, water quality index.

\section{Introduction}

Hyderabad is known for having numerous lakes but due to rapid urbanization and industrialization many of them are encroached and what are existing today are heavily polluted resulting in the degradation of water quality. Continuous discharge of untreated industrial effluents into the water bodies has turned them into 'toxic ponds' [1]. The main sources of drinking water for Hyderabad city are from five impoundments of the following four rivers [2].

- Osmansagar on River Musi.

- Himayatsagar on Esi River

- Manjira River

- Krishna River

The main sources of drinking water to Hyderabad city are shown in Fig.1

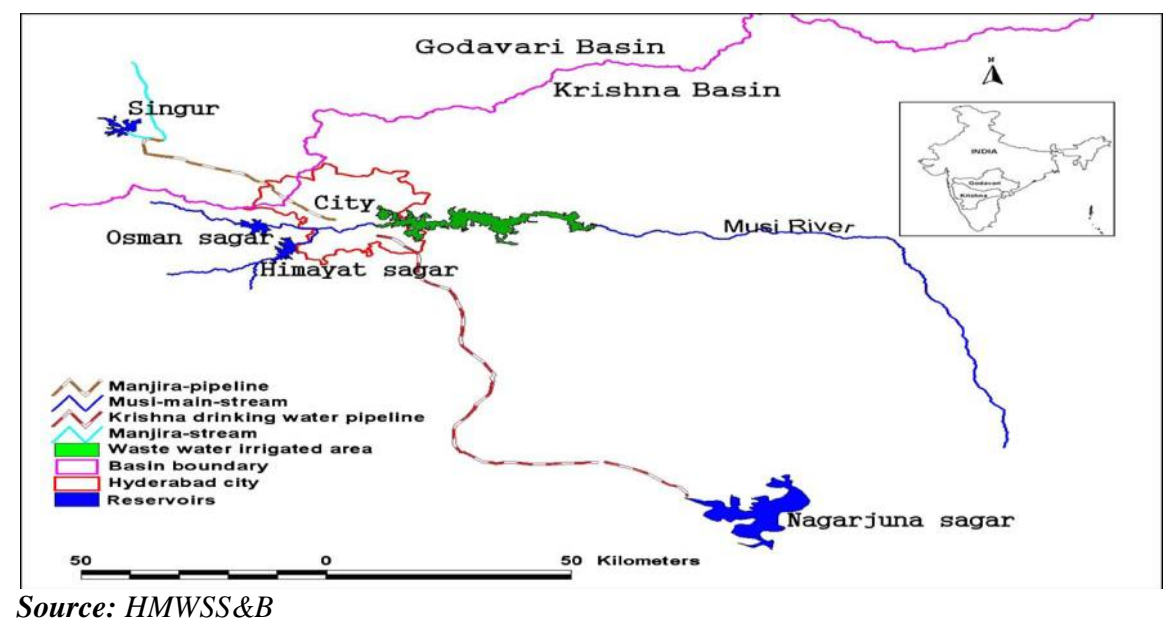

Fig.1 Sources of drinking water to Hyderabad city 
The present water drawls from these reservoirs and their contributions in percentage are given below in Fig.2.

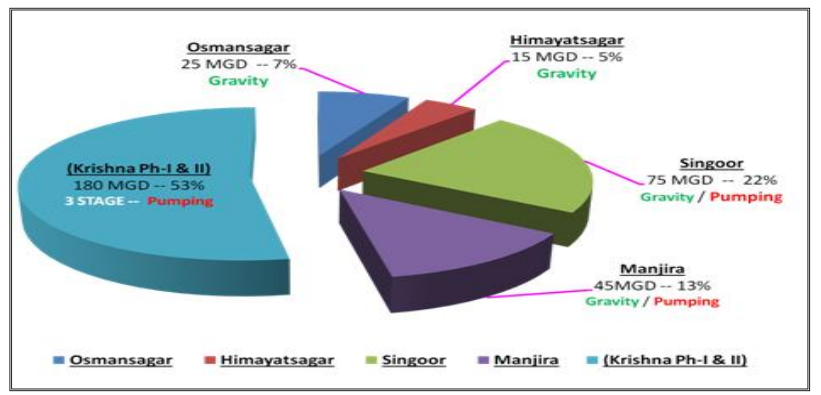

Source: $H M W S S \& B$

Fig.2 Present drawls from the five reservoirs

The oldest man made drinking water sources are Osmansagar, built in 1920 across Musi and Himayatsagar in 1927 across Esi, a tributary of Musi river [3].These two lakes were built in order to control floods in Hyderabad. Before these two reservoirs were built Hussainsagar and Mir Alam Tank (built in 1562 and 1908 respectively) were major drinking water sources to the city till 1930 . Over the years, the latter two got polluted and are no more used as drinking water sources [4]. The Hyderabad Metropolitan Water Supply and Sewerage Board (HMWS\&SB) is a statutory authority in charge of providing and maintaining water supply and sewerage facilities in greater Hyderabad including surrounding municipalities [5].The present study is focused on the assessment of water quality of Himayathsagar Lake in terms of Water Quality Index (WQI).

The Salient features of Himayathsagar Lake are presented in Table1.

Table 1 Salient features of Himayathsagar Lake.

\begin{tabular}{|c|l|l|}
\hline S.No & Item & Description \\
\hline 1 & Date of construction & 1927 \\
\hline 2 & Catchment area & $505 \mathrm{Sq}$. miles \\
\hline 3 & Maximum runoff in the river & $160000 \mathrm{Cusecs}$ \\
\hline 4 & Length of the dam & $7400 \mathrm{ft}$. \\
\hline 5 & Permanent storage level & R.L $1763.00 \mathrm{FTL}$ \\
\hline 6 & Total storage capacity & $10130 \mathrm{MCft}$ \\
\hline 7 & Maximum water level & R.L +1780.00 \\
\hline 8 & Water spread area & $12.60 \mathrm{Sq} . \mathrm{miles}$ \\
\hline 9 & Maximum depth of the water & $84 \mathrm{ft}$ \\
\hline 10 & Flood gates & $17 \mathrm{Nos}$. \\
\hline
\end{tabular}

Source: $H M W S S \& B$

$\boldsymbol{R L}:$ Reservoir length

A study on the lake concluded that the reservoir would dry up completely by 2036 owing to reduced inflows and increasing urbanization [6].If it is not dried up it will receive polluted water as witnessed in Hussainsagar [6]. The city's dependence on this lake for drinking water has reduced in recent times and water from greater distance and high expense is procured to quench the thirst. Constructional activities in the residential areas are taking place at a faster pace in the adjoining villages falling under the catchment areas. The lake is polluted by sewage from the villages. The waste generated by the poultry farms \& resorts and the pesticides used by the farmers for cultivation joins the lake water during rainy season. Nutrient addition coupled with organic pollution has resulted in increased algal activity and reduced dissolved oxygen levels. In general the water color of the lake is fairly green and often turns to brown during summer season. Fish mortality has been recorded frequently. If the agricultural and constructional activities are controlled in the catchment areas this precious resource can be saved for future use.

\section{Methodology}

The raw water samples from the Himayathsagar lake are analyzed for the physicochemical characteristics for a period of one year from August 2013 to September 2014. The samples were analyzed for three seasons at different locations for a number of physicochemical and biological parameters using standard procedures recommended by American Public Health Association (APHA) 1998 [7] and National Environmental Engineering Research Institute (NEERI) (1986) [8]. 


\subsection{Water Quality Index (WQI) for assessment of Lake water}

Water quality is affected by the quantity and quality of supplies coming from different sources. To provide a comprehensive but easy to use tool in the assessment and evaluation of water quality, the concept of Water Quality Index (WQI) has been developed [9].It provides "ranking of water quality" with a single number that express overall water quality based on several parameters. Water quality index is calculated for Himayathsagar using the protocol of National Sanitation Foundation (1970). It is determined on the basis of 9 important parameters viz., pH, temperature, turbidity, total solids, nitrates, phosphates, dissolved oxygen, biochemical oxygen demand and faecal coliforms. The average values of the samples at different locations for all the nine parameters are compared to the corresponding standard curves provided by the National Sanitation Foundation (NSF) Brown et al., (1970) [10] and a numerical value or "Q- value" is obtained. Thus, water quality index is obtained after the Q- value is multiplied by a "weighting factor" based on that particular test's importance in water quality. The values range from 0-100 and the streams are classified from very bad to excellent.

The quality of the water, based on the WQI values is shown inTable 2.

Table 2 Water Quality Index Legend

\begin{tabular}{|c|c|}
\hline Range & Quality \\
\hline $91-100$ & Excellent \\
\hline $71-90$ & Good \\
\hline $51-70$ & Medium \\
\hline $26-50$ & Bad \\
\hline $0-25$ & Very bad \\
\hline
\end{tabular}

\section{Results And Discussions}

Mean values of physicochemical and biological parameters of raw water of Himayathsagar Lake of the three seasons-winters, summer and rainy for the calculation of water quality index are presented in the Table 3 .

Table 3 Water Quality Index for Himayathsagar Lake (Season wise).

\begin{tabular}{|c|c|c|c|c|c|c|c|c|c|c|}
\hline \multirow[b]{2}{*}{ S.No } & \multirow[b]{2}{*}{ Parameters } & \multicolumn{3}{|c|}{ Winter } & \multicolumn{3}{|c|}{ Summer } & \multicolumn{3}{|c|}{ Rainy } \\
\hline & & Avg. & $\mathrm{Q}$ value & WQI & Avg. & $Q$ value & WQI & Avg. & Q value & WQI \\
\hline 1 & $\mathrm{pH}$ & 7.8 & 88 & 9.68 & 7.9 & 87 & 9.57 & 7.9 & 87 & 9.57 \\
\hline 2 & Temperature $\left({ }^{\circ} \mathrm{C}\right)$ & 26.0 & 14 & 1.4 & 29.5 & 11 & 1.1 & 27 & 13 & 1.3 \\
\hline 3 & Turbidity(NTU) & 16.8 & 65 & 5.2 & 35.5 & 49 & 3.92 & 173.5 & 5 & 0.4 \\
\hline 4 & Total solids $(\mathrm{mg} / \mathrm{L})$ & 3.4 & 80 & 5.6 & 3.4 & 80 & 5.6 & 3.5 & 80 & 5.6 \\
\hline 5 & $\mathrm{DO}(\mathrm{mg} / \mathrm{L})$ & 3.9 & 12 & 2.04 & 3.7 & 12 & 2.04 & 4.1 & 13 & 2.21 \\
\hline 6 & $\mathrm{BOD}(\mathrm{mg} / \mathrm{L})$ & 2.8 & 68 & 7.48 & 3.0 & 67 & 7.37 & 3.1 & 66 & 7.26 \\
\hline 7 & Total phosphates $(\mathrm{mg} / \mathrm{L})$ & 0.12 & 95 & 9.5 & 0.34 & 77 & 7.7 & 0.1 & 96 & 9.6 \\
\hline 8 & Nitrates $(\mathrm{mg} / \mathrm{L})$ & 8.9 & 53 & 5.3 & 2.3 & 94 & 9.4 & 1.2 & 96 & 9.6 \\
\hline 9 & $\begin{array}{l}\text { Faecal Coliforms } \\
(\mathrm{CFU} / 100 \mathrm{ml})\end{array}$ & 51 & 52 & 8.32 & 137 & 41 & 6.56 & 75 & 47 & 7.52 \\
\hline \multicolumn{4}{|c|}{ WQI } & 54.56 & & & 53.26 & & & 53.06 \\
\hline
\end{tabular}

The water quality index for winter, summer and rainy seasons are 54.56, 53.26, and 53.06 respectively. The WQI values for all the seasons indicate medium water quality of the lake. The water quality as per the WQI values is slightly poorer in rainy season than in winter and summer seasons. The poor water quality in rainy season can be attributed to dissolution of various nutrients during rains and algal vegetation.

The overall water quality of the Himayathsagar Lake by taking the average of three seasons is presented inTable 4 .

Table 4. Overall Water Quality Index of Himayathsagar Lake.

\begin{tabular}{|c|l|c|c|c|c|c|}
\hline S.No. & Parameters & $\begin{array}{l}\text { IS : 10500- } \\
(\mathbf{2 0 1 2})\end{array}$ & $\begin{array}{l}\text { Seasonal } \\
\text { Average }\end{array}$ & $\begin{array}{l}\text { Observed } \\
\text { Q-value }\end{array}$ & $\begin{array}{l}\text { Unit } \\
\text { weight }\end{array}$ & $\begin{array}{l}\text { WQI= Observed Q } \\
\text { value X weight }\end{array}$ \\
\hline 1 & $\mathrm{pH}$ & $6.5-8.5$ & 7.89 & 87 & 0.11 & 9.51 \\
\hline 2 & Temperature $\left({ }^{\circ} \mathrm{C}\right)$ & - & 27.5 & 13 & 0.10 & 1.3 \\
\hline 3 & Turbidity $(\mathrm{NTU})$ & 1 & 75.2 & 27 & 0.08 & 2.16 \\
\hline 4 & Total solids $(\mathrm{mg} / \mathrm{L})$ & $\mathrm{NS}$ & 3.46 & 80 & 0.07 & 5.6 \\
\hline 5 & DO $(\mathrm{mg} / \mathrm{L})$ & 8 & 3.9 & 12 & 0.17 & 2.04 \\
\hline 6 & BOD $(\mathrm{mg} / \mathrm{L})$ & - & 3 & 67 & 0.11 & 7.37 \\
\hline 7 & Total phosphates(mg/L) & - & 0.50 & 60 & 0.10 & 6 \\
\hline 8 & Nitrates $(\mathrm{mg} / \mathrm{L})$ & 45 & 4.13 & 69 & 0.10 & 6.9 \\
\hline 9 & Faecal Coliforms & Absent & 87.6 & 46 & 0.16 & 7.36 \\
\hline
\end{tabular}


Assessment of Water Quality of Himayathsagar Lake in Hyderabad - A Case study.

\begin{tabular}{|l|l|l|l|l|}
\hline & $(\mathrm{CFU} / 100 \mathrm{ml})$ & & & \\
\hline \multicolumn{3}{|c|}{} & WQI & $\mathbf{4 8 . 2 4}$ \\
\hline
\end{tabular}

NS-Not specified

The overall WQI value for Himayathsagar lake indicate slightly poor water quality of the lake. All the parameters studied are within the permissible limits of Indian Standards (IS:10500-2012) except faecal coliforms. The presence of faecal coliforms indicate that the lake water is highly contaminated.

\subsection{Calculation of Correlation Coefficient (r)}

The correlation coefficient $(\mathrm{r})$ between different parameter pairs is computed by taking the average values of the winter, summer and rainy seasons of the Himayathsagar lake water. Correlation coefficient ( $r$ ) between parameters $\mathrm{x}$ and $\mathrm{y}$ is calculated for parameters like water temperature, $\mathrm{pH}$, total dissolved salts, electrical conductivity, turbidity, total hardness, total alkalinity, chloride, sulphate, nitrate, phosphate ,dissolved oxygen, biological oxygen demand and chemical oxygen demand.

The average values of the physicochemical parameters for winter, summer and rainy seasons are shown in Table 5.

Table 5 Seasonal average and statistical characteristics of Himayathsagar Lake

\begin{tabular}{|l|c|c|c|c|c|c|c|}
\hline \multirow{2}{*}{\multicolumn{1}{|c|}{ Parameter }} & \multicolumn{3}{c|}{ Seasonal average } & \multicolumn{4}{c|}{ Statistical Parameters } \\
\cline { 2 - 8 } & Winter & Summer & Rainy & Min & Max & Mean & SD \\
\hline Water temperature $\left({ }^{\circ} \mathrm{C}\right)$ & 26 & 29.5 & 27 & 26 & 29.5 & 27.5 & 1.803 \\
\hline $\mathrm{pH}$ & 7.8 & 7.9 & 7.9 & 7.8 & 7.9 & 7.87 & 0.058 \\
\hline TDS(mg/L) & 197.7 & 250 & 136 & 136 & 250 & 194.57 & 57.065 \\
\hline Conductivity(ms) & 395.5 & 415 & 220 & 220 & 415 & 343.50 & 107.398 \\
\hline Turbidity(NTU) & 16.8 & 35.5 & 173.5 & 16.8 & 173.5 & 75.27 & 85.585 \\
\hline Total hardness(mg/L) & 135 & 167 & 81 & 81 & 167 & 127.67 & 43.466 \\
\hline Total alkalinity (mg/L) & 124 & 166 & 85 & 85 & 166 & 125.00 & 40.509 \\
\hline Chloride(mg/L) & 45 & 34 & 20 & 20 & 45 & 33.00 & 12.530 \\
\hline Sulphate(mg/L) & 12.2 & 8 & 5 & 5 & 12.2 & 8.40 & 3.617 \\
\hline Nitrate(mg/L) & 8.9 & 2.3 & 1.2 & 1.2 & 8.9 & 4.13 & 4.165 \\
\hline Phosphate(mg/L) & 0.12 & 0.34 & 0.1 & 0.1 & 0.34 & 0.19 & 0.133 \\
\hline DO(mg/L) & 3.9 & 3.7 & 4.1 & 3.7 & 4.1 & 3.90 & 0.200 \\
\hline BOD(mg/L) & 2.8 & 3.05 & 3.12 & 2.8 & 3.12 & 2.99 & 0.168 \\
\hline COD(mg/L) & 28 & 6 & 14 & 6 & 28 & 16.00 & 11.136 \\
\hline
\end{tabular}

SD-Standarddeviation

The correlation between various parameters is presented as a 14 x 14 Correlation matrix in Table 6 .

Table 6 Correlation coefficient (r) between physicochemical parameters of Himayathsagar Lake

\begin{tabular}{|c|c|c|c|c|c|c|c|c|c|c|c|c|c|c|}
\hline & WT & $\mathrm{pH}$ & TDS & EC & TUR & TH & TA & $\mathrm{Cl}$ & $\mathrm{S}$ & $\mathrm{N}$ & $\mathrm{P}$ & DO & BOD & COD \\
\hline WT & 1 & & & & & & & & & & & & & \\
\hline $\mathrm{pH}$ & 0.720577 & 1 & & & & & & & & & & & & \\
\hline TDS & 0.658326 & -0.04755 & 1 & & & & & & & & & & & \\
\hline EC & 0.327327 & -0.41931 & 0.926754 & 1 & & & & & & & & & & \\
\hline TUR & -0.1327 & 0.591619 & -0.83344 & -0.97999 & 1 & & & & & & & & & \\
\hline $\mathrm{TH}$ & 0.580651 & -0.14611 & 0.995097 & 0.959364 & -0.88401 & 1 & & & & & & & & \\
\hline TA & 0.708622 & 0.021378 & 0.997624 & 0.89867 & -0.79339 & 0.985919 & 1 & & & & & & & \\
\hline $\mathrm{Cl}$ & -0.21028 & -0.8294 & 0.597468 & 0.854953 & -0.94109 & 0.673848 & 0.540802 & 1 & & & & & & \\
\hline $\mathrm{S}$ & -0.3681 & -0.90993 & 0.457551 & 0.758076 & $\begin{array}{l}-0.87271 \\
\end{array}$ & 0.54325 & 0.395203 & 0.986402 & 1 & & & & & \\
\hline $\mathbf{N}$ & -0.62269 & -0.99124 & 0.179054 & 0.535537 & -0.69291 & 0.27548 & 0.110846 & 0.895912 & 0.95674 & 1 & & & & \\
\hline$P$ & 0.937229 & 0.433555 & 0.879491 & 0.636285 & -0.47001 & 0.82811 & 0.91019 & 0.143836 & -0.02076 & -0.31075 & 1 & & & \\
\hline DO & -0.69338 & 0 & -0.99887 & -0.90784 & 0.806218 & -0.98927 & -0.99977 & -0.55866 & -0.41475 & -0.13207 & -0.90113 & 1 & & \\
\hline BOD & 0.56055 & 0.978117 & -0.25433 & -0.59902 & 0.746409 & -0.34873 & -0.1871 & -0.92748 & -0.97631 & -0.99703 & 0.236585 & 0.208053 & 1 & \\
\hline COD & -0.92155 & -0.93326 & -0.31443 & 0.065221 & -0.26253 & -0.219 & -0.37908 & 0.573363 & 0.70022 & 0.877642 & -0.72831 & 0.359211 & -0.8381 & 1 \\
\hline
\end{tabular}

WT $=$ Water temperature, TDS=Total dissolved salts, EC= Electrical conductivity, TUR= Turbidity, TH= Total hardness, TA= Total Alkalinity, $\mathrm{Cl}=$ Chloride, $\mathrm{S}=$ Sulphate, $\mathrm{N}=$ Nitrate, $\mathrm{P}=$ Phosphate, $\mathrm{DO}=$ Dissolved oxygen, $\mathrm{BOD}=\mathrm{Biological}$ oxygen demand, $\mathrm{COD}=\mathrm{Chemical}$ oxygen demand.

Water temperature is found to show positive correlation with $\mathrm{pH}$, total dissolved salts, electrical conductivity, total hardness, total alkalinity, phosphate and biological oxygen demand. Electrical conductivity showed a positive correlation with total hardness, total alkalinity, chloride and nitrate and a strong negative correlation $(r=-0.97999)$ with turbidity. There is a strong positive correlation between total dissolved salts \& total alkalinity $(r=0.997624)$. A strong negative correlation $(r=-0.99977)$ between dissolved oxygen and total alkalinity is observed. There is no correlation between $\mathrm{pH}$ and dissolved oxygen. The correlation coefficient ( $\mathrm{r}$ ) values ranging from 0.400 to $0.52 \& 0.53$ and above are significant at $\mathrm{P}<0.05$ and $\mathrm{P}<0.01$ respectively. 


\section{Conclusions and Recommendations}

Rapid urbanization and industrialization has led to unchecked proliferation of hazardous industries in and around Hyderabad. The area surrounding Himayathsagar lake has ample possibilities of organic pollution, heavy metals and pesticides contamination from various sources viz., domestic waste water, agriculture/horticulture runoff, laboratory waste from educational institutes, solid waste disposal, vegetation in the lake and human activities. As a result, the water quality index of the lake is lowered to 48.24 indicating slightly poor water quality. The lake boundaries should be clearly demarked and fenced to stop encroachments \& curb anthropogenic activities. The nonpoint sources of pollutants entering the lake including fertilizers, toxic pesticides and other chemicals from agriculture runoff should be identified . The government should strictly implement GO-111 in curbing all activities in the catchment area of the lake leading to deterioration in water quality. The authorities can think of introducing some specific types of fishes into the lake which would help in cleansing the water. The sewage water from the villages in the catchment area due to poor drainage system is another source of contamination which can be checked by constructing regional sewerage treatment plants. As the lake is closer to the city, protecting it from pollution is of utmost importance as the water can be a precious resource in case of emergency.

\section{Acknowledgement}

The author is grateful to the management of Vignana Jyothi Institute of Engineering and Technology for providing a good platform for research and also thankful to the officials of HMWSS\&B for their necessary help and support rendered during the study.

\section{References}

[1]. Kishan Rao, A. Patancheru-A Hell on Earth (A Saga of a People's Struggle Against Industrial Pollution), A.V.R.R. Memorial Charitable Trust, Hyderabad (2001).

[2]. Hyderabad Metropolitan Water Supply and Sewerage Board (HMWSS\&B).

[3]. Alikhan, R. "Hyderabad: 400 years (1951-1991)". Hyderabad: View Point (1990).

[4]. Ramachandraiah, Chigurupati, Vedakumar, Manikonda., "Hyderabad's Water Issues and the Musi River Need for Integrated Solutions", Paper presented in the International Water Conference, Berlin during 12-14 September(2007).

[5]. http://cseindia.org/userfiles/hyderabad_portraits.pdf

[6]. C. Ramachandraiah Sheela Prasad, "Impact of Urban Growth on Water Bodies. The Case of Hyderabad", Centre for economic and social studies, Hyderabad Working Paper No. 60 (2004).

[7]. APHA...Standard methods for the examination of water and wastewater. American Public Health Association, 20 ${ }^{\text {th }}$ edition Washington DC (1998).

[8]. NEERI (1986), Manual on water and waste water analysis, National Environmental Engineering Research Institute, Nagpur-P-340.

[9]. Fuzhan nasiri, Imran Maqsood, Gordor Huang and Norma Fuller (2007)"Water Quality Index: A Fuzzy River-Pollution Decision Support Expert System” Journal of Water Resources Planning and Management 133( 2) pp 95-105.

[10]. Brown, R.M., McLelland, N.J., Deininger, RA.and Tozer, R.G. (1970) “A Water Quality Index Do We Dare?” Water \& Sewage Works 117(10), pp 339-343. 